\title{
High Speed Milling of a Large Thin Sheet Copper Part with a Vacuum Fixture on a CNC Machine Tool
}

\author{
Y. CAO*, 1 and J. L. SHI ${ }^{2}$ \\ ${ }^{1}$ School of Mechatronic Engineering, Xi'an Technological University, Xi'an 710032, China \\ ${ }^{2}$ School of Mechanical Engineering, Xi'an Jiaotong University, Xi'an 710029, China \\ *Corresponding author: jantonyz@163.com
}

Keywords: High Speed Milling, Thin Sheet Part, Vacuum Fixture, Deformation.

\begin{abstract}
Aiming at the machining difficulty of a large thin sheet part, high speed milling and a vacuum fixture are used to reduce its machining deformation and errors. The vacuum fixture suitable for the machining of the large thin sheet part is designed and fabricated. It is able to clamp the large thin sheet part rapidly and reduce its clamping deformation and errors. High speed milling is also adopted to machine the large thin sheet part. On the one side, it can improve processing efficiency. On the other side, it can also reduce processing deformation. Thereby, the part's machining quality and precision are assured. Based on a number of processing tests and improvements, rational cutting parameters are obtained to machine the part that achieve less cutter damage, higher productivity and low production costs. The finished part satisfies its machining requirements. The presented approach is approved to be effective and efficient for similar large thin sheet part machining.
\end{abstract}

\section{Introduction}

In modern machining, there are several puzzling problems. One is the turning of slender shafts and thin-walled parts. The other is the milling of thin-walled parts and thin sheet parts.

There are many researches and experience for the former problem that can be referred. But there are fewer researches on the latter one. The shape and structure of the thin-walled parts ${ }^{[1]}$ and thin sheet parts vary greatly. The thin sheet parts are widely used in aviation, spaceflight, war industry, medical treatment products, etc. Due to their poor rigidity, they are prone to deform under the effect of clamping and cutting forces, which leads to size errors or damaged parts in milling. Therefore, bench work is needed to level the thin sheet parts, which spends a lot of time. Rework is often required. As a result, their machining efficiency is low. These problems have been puzzling mechanical machining for many years.

In the paper, a large sheet copper part is milled on a CNC machine tool that is $1500 \mathrm{~mm}$ long, $700 \mathrm{~mm}$ wide and $4 \mathrm{~mm}$ thick, as shown in figure 1 . A $3 \mathrm{~mm}$ deep spiral slot is milled on its one side. Because the part is only $4 \mathrm{~mm}$ thick, its processing depth must be controlled carefully. Otherwise, on the one side, copper scales may be left on the bottom of the slot; on the other side, the part may be penetrated by a milling cutter and scraped. 


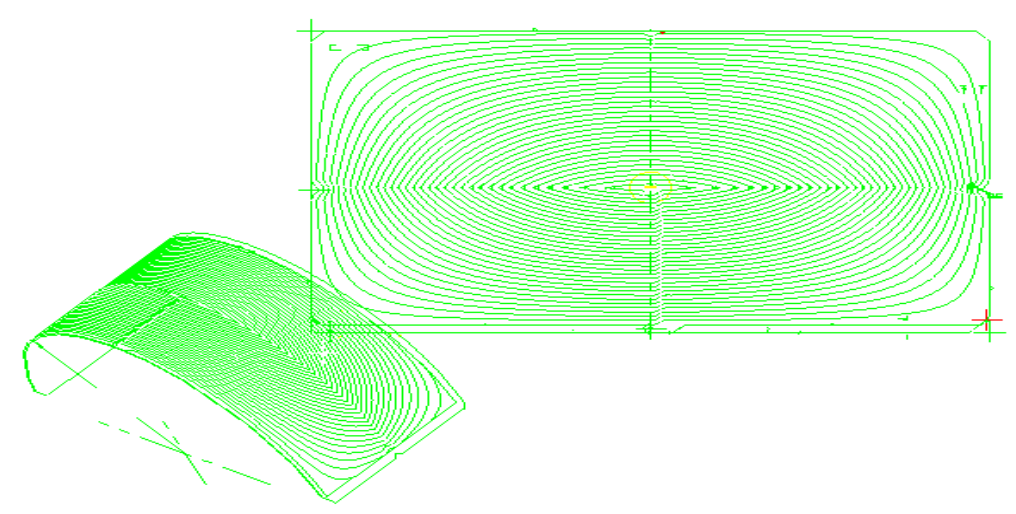

Figure 1 The thin sheet part and its expansion figure.

\section{Experimental Procedure}

In the paper, the research scheme ${ }^{[2-3]}$ is shown in figure 2 as below.

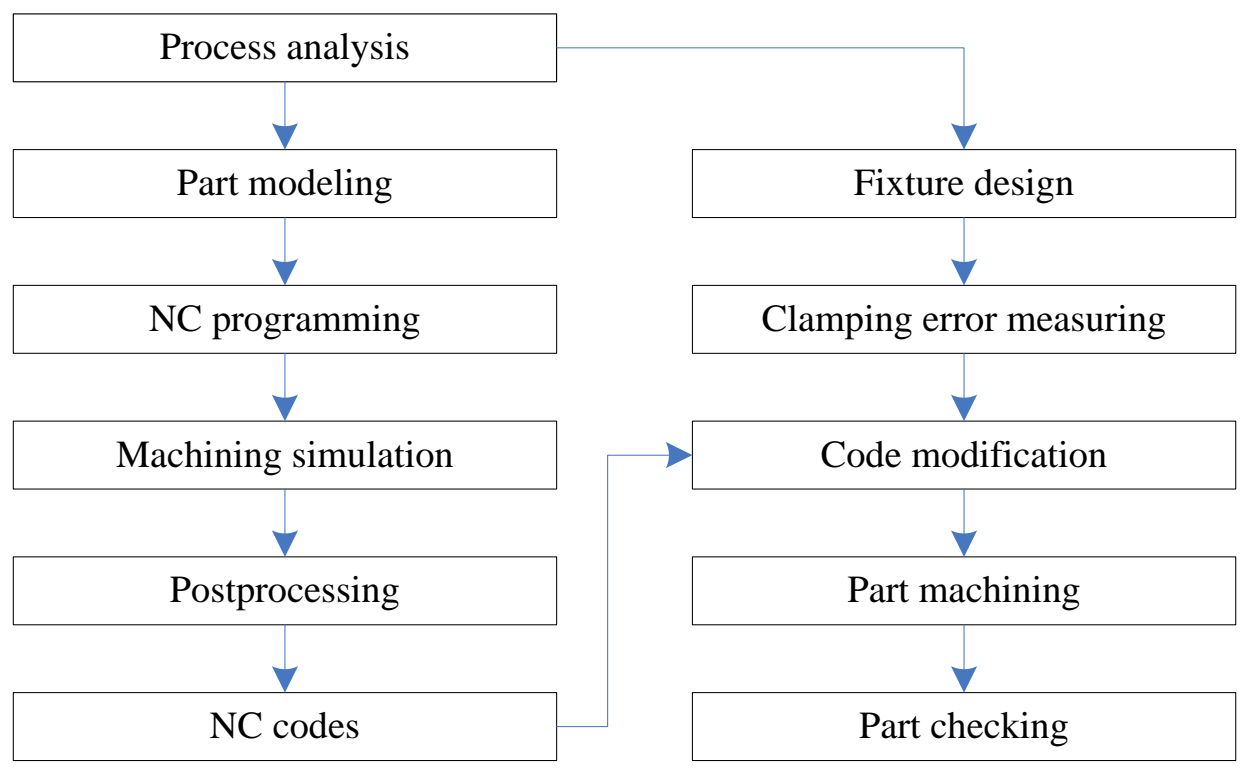

Figure 2 The research scheme.

\section{Part Clamping with a Special Vacuum Fixture}

The number, location and magnitude of clamping forces affect part's deformation. In order to reduce large local deformation and average the whole deformation of the part, distributed clamping force is applied. Centralized clamping forces are applied only to the part's rigid edges and distributed sucking force is applied to the less rigid part surface. The least clamping forces are applied as long as they can assure the part's reliable machining.

According to the clamping difficulty of the thin sheet part, a clamping scheme is put forward. The thin sheet part is pressed on its edges with some hold-down strips and sucked with a specially designed vacuum fixture on one side of the part from below. First, the thin sheet part is flattened by the hold-down strips. Then, the vacuum fixture sucks one side of the part to clamp it tightly on the fixture, as shown in figure 3. 


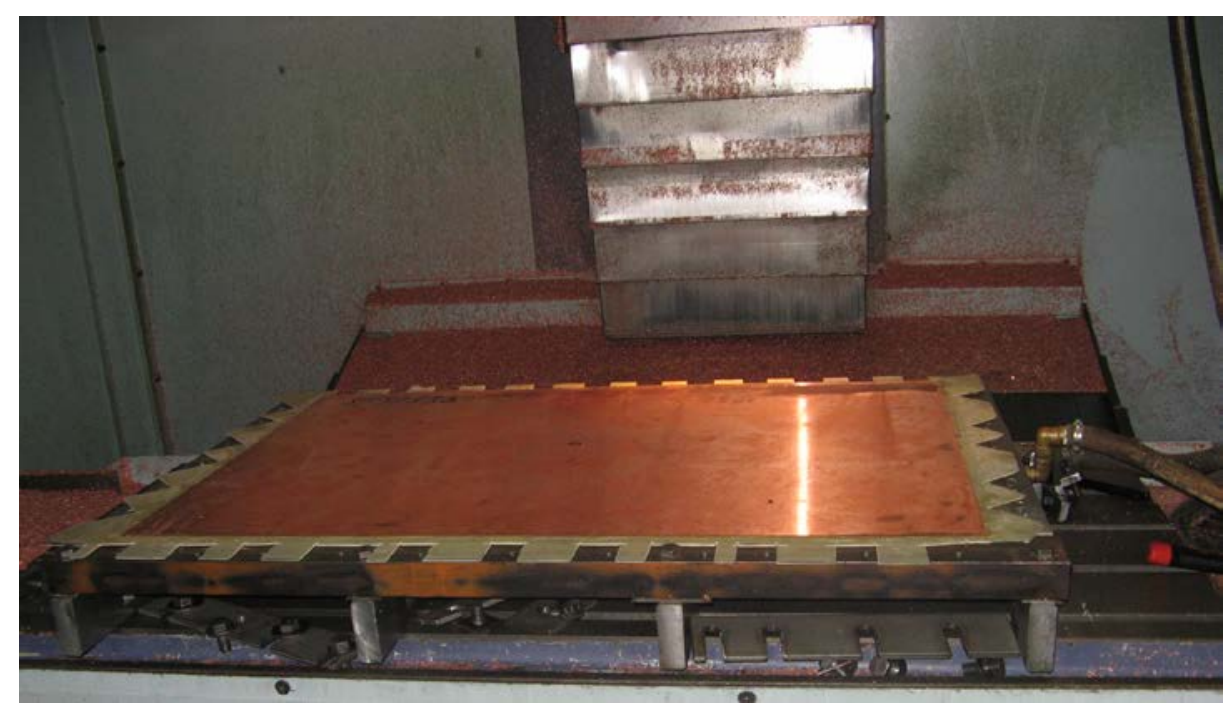

Figure 3 The part installed on the vacuum fixture

\section{Cutting Force}

In milling, the diameter of the adopted milling cutter is 3mm. The cutting depth is 3mm. The cutting forces of the sintered-carbide end milling cutter ${ }^{[4]}$ can refer to Mechanical Processing Technology Manual. The suction can be calculated in terms of the pressure and area of the vacuum fixture. By calculation, the suction is sufficient for the milling of the part. What is more, the hold-down strips also apply additional clamping forces. Therefore, the clamping scheme is feasible.

\section{High speed NC Milling}

For thin sheet parts, they deform badly due to clamping forces and cutting forces and the deformation rebounds badly. The main problems of the part milling are machining deformation and cutting efficiency. Thereby, high speed milling is adopted.

In traditional NC machining, stress needs to be released again and again, which leads to redundant processes and low efficiency. However, in high speed milling, such problems can be effectively solved. In order to exert the advantages of high speed milling, cutting paths must be carefully dealt with according to the part's structure. In order to reduce the errors caused by the part deformation, its cutting paths are optimized $^{[5-7]}$.

\section{High speed NC Programming}

The programming software adopted is EZ-CAM, which is of many advantages in 2D NC programming. It is convenient to modify cutting paths, reduce cutter lifting and so on.

After analyzing the part's structure to be milled, according to high speed milling principles, a milling process flowchart is made suitable for EZ-CAM. Then, a geometric graph is drawn, its tool paths are determined and milling method and tool is also selected. After some manual modifications, NC programs are finally generated.

In high speed milling, not only high spindle rotation speed is required, but also fast feed rate is needed. However, if the feed rate is too fast, it may lead to chattering that reduces machining quality and damages the cutter and machine lead screw. This demands us to make the NC programs suitable for high speed milling to the best of our abilities in order to assure the machine's smooth running.

\section{Use of a speed Increaser}

In general, high speed milling requires high spindle rotation speed. However, the spindle rotation speed of common NC machines can only reach 5000-6000rpm. If a machine has worked at that speed for a long time, it may damage its spindle. Therefore, in the paper, a speed increaser is adopted to increase the spindle rotation speed from $5000 \mathrm{rpm}$ to $30000 \mathrm{rpm}$. Thus, although the machine runs at $18000 \mathrm{rpm}$, it will not damage the spindle. 


\section{Cutting Fluid}

Several cutting fluids are tested in milling. On the one side, decide which cutting fluid is suitable for the part's milling. On the other side, observe their effects on the fixture and part. By comparison, it is found that kerosene can reduce burr generation and has less effect on the vacuum fixture. Even though a little of kerosene is sucked into the vacuum fixture, it can be easily separated by its filter. And the inspiratory amount is little, so it basically does not affect the milling process.

\section{Cutting Tool Fesign}

For thin sheet part machining, usually the cutter of 2-3 teeth is preferred. If the cutter of more teeth is chosen, it increases cutting forces and chip removal difficulty. However, if the cutter of fewer teeth is chosen, it affects cutting stability. From the point of view to reduce cutting force, large rake and back angle are preferred and helical angle should be $30-45^{\circ}$. Too large helical angle increases axial force and too small helical angle increases chip removal difficulty.

According to the structural characteristics of the part, a milling cutter is designed. Its cutting edge length is equal to the cutting depth of the part. The diameter of cutter arbor is greater than that of the cutting edge so as to assure machining accuracy and increase cutter endurance.

\section{Spindle Rotation Speed Optimization}

There is a restriction on the spindle rotation speed. If the speed is too fast, the cutter is prone to break and noise increases when there is some vibration. By tests, it is found that the noise is the least and the cutter is not prone to break if the spindle speed is $6500 \mathrm{rpm}$.

\section{Feed Rate Optimization}

Feed rate also affects machining stability of the part. Increasing the feed rate results in cutting force increment. But this does not mean that a smaller feed rate is better. The smaller the feed rate is, the greater deformation coefficient and friction coefficient are. This may cause greater vibration. However, when the feed rate is too great, the vibration increases due to too great cutting force. According to cutting tests, the selected feed rate is $0.005 \mathrm{~mm} / \mathrm{r}$ that causes less noise and improves cutter durability.

\section{Results and discussion}

- The large special vacuum fixture is designed and fabricated to mill the thin sheet part that converts centralized clamping forces to distributed clamping force. Thus, it reduces large local deformation and part's whole deformation. The thin sheet part is flattened by the hold-down strips and the vacuum fixture sucks one side of the part to clamp it tightly on the fixture. The least clamping forces are applied as long as they can assure its reliable machining. By adopting such a clamping scheme, the clamping deformation of the part is reduced from $1 \mathrm{~mm}$ to about $0.4 \mathrm{~mm}$.

- By using the speed increaser, the CNC machine is more suitable for high speed milling. It expands the machining capability. Because the NC programs are carefully optimized according to high speed milling requirements, not only machining efficiency is improved, but also the deformation in milling is reduced. Accordingly, the part machining quality and accuracy are enhanced.

- On the one side, the cutting parameters are optimized. On the other side, the NC programs are also improved to take the part deformation and rebound in machining into account. Finally, the deformation rebound and its effect on the part machining quality are reduced. Thus, the machining time and costs are reduced.

\section{Conclusions}

In mechanical machining, the milling of the thin sheet parts is always a problem. Researchers and technicians have been exploring how to solve their deformation in machining. In the paper, based on high speed milling and the special vacuum fixture, many measures are adopted to reduce the clamping deformation and machining deformation of the thin sheet part and to effectively control the deformation. Through a number of processing tests and improvements, the rational cutting parameters are 
obtained to mill the part that achieve less cutter damage, higher productivity and low costs. The finished part satisfies the machining requirements.

\section{Acknowledgements}

The work is supported by National Natural Science Foundation Project (11302159), Open Research Fund Program of Shaanxi Key Laboratory of Non-Traditional Machining (ST-11003) and Key Problem Tackling Project of Shaanxi Scientific and Technological Office (2012K06-19).

\section{References}

[1] He, N., Wang, Z.G., Jiang, C.Y. \& Zhang, B., Finite element method analysis and control stratagem for machining deformation of thin-walled components. Journal of Materials Processing Technology, 139, pp. 332-336, 2003.

[2] Tarng, Y.S., Cheng, C.I. \& Kao, J.Y., Modeling of three-dimensional numerically controlled end milling operations. International Journal of Machine Tools \& Manufacture, 35, pp. 939-950, 1995.

[3] Xu, A.P., Qu, Y.X., Zhang, D.W. \& Huang, T., Simulation and experimental investigation of the end milling process considering the cutter flexibility. International Journal of Machine Tools \& Manufacture, 43, pp. 283-292, 2003.

[4] Liu, X.W., Cheng, K., Webb, D. \& Luo, X.C., Prediction of cutting force distribution and its influence on dimensional accuracy in peripheral milling. International Journal of Machine Tools \& Manufacture, 42, pp. 791-800, 2002.

[5] Law, K.M.Y., Geddam, A. \& Ostafiev, V.A., A process-design approach to error compensation in the end milling of pockets. Journal of Materials Processing Technology, 89-90, pp. 238-244, 1999.

[6] Law, K.M.Y. \& Geddam, A., Error compensation in the end milling of pockets: a methodology, Journal of Materials Processing Technology, 139, pp. 21-27, 2003.

[7] Cho, M.W., Seo, T. \& Kwon, H. D., Integrated error compensation method using OMM system for profile milling operation. Journal of Materials Processing Technology, 136, pp. 88-99, 2003. 